\title{
Two-level total lumbar disc replacement
}

\author{
Mario Di Silvestre • Georgios Bakaloudis • \\ Francesco Lolli · Francesco Vommaro • \\ Patrizio Parisini
}

Accepted: 14 March 2009/Published online: 28 April 2009

(C) Springer-Verlag 2009

\begin{abstract}
Total lumbar disc replacement (TDR) has been widely used as a treatment option for 2-level symptomatic degenerative disc disease. However, recent studies have presented conflicting results and some authors concluded that outcome deteriorated when disc replacement was performed bisegmentally, with an increase of complications for bisegmental replacements in comparison with monosegmental disc arthroplasty. The goal of the present retrospective study is to investigate results in a group of patients who have received bisegmental TDR with SB Charitè III artificial disc for degenerative disc disease with a minimum follow-up of 3 years, and to compare the results of 2-level disc replacement versus 1-level patients treated with the same prosthesis. A total of 32 patients had at least 3-years follow-up and were reviewed. The average age of the patients was 38.5 years. There were 11 males and 21 females. About 16 patients received 2-level TDR (SB Charitè III) and 16 received 1-level TDR (SB Charitè III). Both radiographic and functional outcome analysis, including patient's satisfaction, was performed. There were no signs of degenerative changes of the adjacent segments in any case of the 2- or 1-level TDR. There was no statistically significant difference between 2- and 1-level TDR both at 12 months and at 3-years follow-up on functional outcome scores. There was a statistically insignificant difference concerning the patients satisfaction between 1and 2-level surgeries at the last follow-up $(P=0.46)$. In the 2-level TDR patients, there were 5 minor complications
\end{abstract}

M. Di Silvestre $(\bowtie)$ · G. Bakaloudis · F. Lolli · F. Vommaro · P. Parisini

Spine Surgery Department, Istituti Ortopedici Rizzoli,

Via Pupilli 1, 40136 Bologna, Italy

e-mail: mario.disilvestre@ior.it
$(31.25 \%)$, whereas major complications occurred in 4 more patients $(25 \%)$ and required a new surgery in 2 cases (12.5\%). In the 1-level cases there were 2 minor complications (12.5\%) and 2 major complications (12.5\%) and a new revision surgery was required in 1 patient $(6.25 \%)$. In conclusion, the use of 2-level disc replacement at last follow-up presented a higher incidence of complications than in cases with 1-level replacement. At the same time it was impossible to delineate a clear difference in evaluating the questionnaires between the follow-up results of patients receiving 2- and 1-level TDR: the 2-level group presented slightly lower scores at follow-up, but none was statistically significant.

Keywords Total disc replacement - Bisegmental disc replacement - Degenerative disc disease - Lumbar spine

\section{Introduction}

Total lumbar disc replacement (TDR) has become increasingly popular for treatment of lumbar degenerative disc disease [3, 13, 15, 17, 18, 22, 26-29].

Two-level and multisegmental TDR also appeared to be a safe and efficacious treatment method: arthroplasty has been used at 2 or 3 contiguous levels with a high success rate $[3,24]$. However, results from a study by Siepe et al. [23] indicated a significant influence of the number of discs replaced on postoperative outcome: postoperative results further deteriorated when disc replacement was performed bisegmentally using ProDisc II prosthesis, with an increase in complications for bisegmental replacements in comparison with monosegmental disc arthroplasty. Previous studies $[6,8]$ concluded that the SB Charite' implant is not recommended for multisegmental disc replacement due to 
increased intersegmental distraction related to the biconvex-shaped polyethylene core. Instead, in a prospective study [30] arthroplasty with ProDisc II was a viable treatment option for 2-level symptomatic degenerative disc disease, without showing any significant difference between 1- and 2-level patients. Likewise, Hannibal et al. [13] were unable to delineate a clear difference between the postoperative results of patients receiving 1- and 2- level ProDisc II arthroplasty.

The purpose of the present retrospective study is to investigate results in a group of patients receiving bisegmental TDR with SB Charitè III artificial disc for degenerative disc disease with a minimum follow-up of 3 years, and to compare the results of 2-level disc replacement versus 1-level patients treated with the same prosthesis (SB Charite' III).

\section{Materials and methods}

\section{Patients}

Patients who underwent at our Department, mono and bisegmental TDR using SB Charite' III artificial disc for predominantly disabling low-back pain and minimal radicular pain secondary to mono or bisegmental lumbar disc disease, were included in this study. Inclusion criteria were: 1. Not more than 1- or 2-levels of lumbar degenerative disc disease; 2 . Failed conservative treatment for at least 12 months; 3. Pre-operative radiographic study including provocative CT/discography; 4. No previous lumbar surgery (i.e., microdiscectomy, macrodiscectomy, or partial laminectomy); 5. A minimum of 3-year follow-up.

\section{Radiographic assessment}

Surgery was performed after a complete radiographic study, including anteroposterior and lateral flexion/extension X-rays, CT, MRI, and provocative CT/discography. $\mathrm{CT} /$ discography was performed in each patient: a minimum of 2 levels were injected for cases with monosegmental disc disease and a minimum of 3 levels for bisegmental cases. The most important part of CT/discographic evaluation was pain provocation. The responses during the injection were classified according to Sachs et al. [21] from "no pain or pressure sensations only" to "the patient experiences exact reproduction of his clinical symptoms"; pain intensity was evaluated on a 0 -to-10 scale, and positive discography was defined as concordant pain $\geq 6$ out of 10. In all cases CT scan showed lateral tear or a diffuse degeneration throughout the disc, with agreement between the CT/discographic images and the pain responses: the discographic results were, however, combined with other imaging studies, physical examination, and patient history.

\section{Outcome measurements}

Outcomes were measured using the standardised ODI [11, 20], the SF-36 Health Survey (SF-36) [1], and the Visual Analogue Scale (VAS) to rate the pain level. These were filled out at the initial preoperative visit, at 12 months, and at the last visit (minimum 3 years follow-up).

\section{Surgical treatment}

The surgical procedure was the same in all cases, using SB Charitè III artificial disc. The patient's position was supine on a fluoroscopic imaging table with legs adducted. The skin incision was longitudinal and left sided for L5-S1 and for all other levels. An anterior standard left-sided retroperitoneal approach for all levels was performed exposing the level of disease and performing a complete anterior discectomy beginning at the most caudal disc. The posterior longitudinal ligament was sometimes released to remove extruded disc material. After a complete discectomy, the endplates were prepared. Adequate central/midline location of prosthesis was confirmed using AP fluoroscopy. Final implant replacement was performed at the caudal level and the steps were repeated for the upper level. For 1-level surgeries the average intraoperative blood loss was of about $100 \mathrm{ml}$, and for 2-level TDR it was of $250 \mathrm{ml}$. A drainage was never used.

Statistical analysis

Mean and standard deviations were calculated for numerical outcomes. An unpaired $t$-test was done to compare the 2- versus 1-level disc replacement patients.

\section{Results}

\section{Demographic}

A total of 32 patients had at least 3 years minimum followup and met the inclusion criteria for this study. The average age of the patients was 38.5 years. There were 11 males and 21 females. Predominantly all patients had back pain for at least 2 years, but approximately $80 \%$ also noted a lower degree of leg pain. Average body mass index was $28 \mathrm{~kg} / \mathrm{m}^{2}$. About 16 patients received 2-level total Disc replacements (SB Charite' III) and 16 received 1-level replacement (SB Charitè III). The results of patients with 2-level replacement were compared with those obtained with 1-level replacement. The two groups were well 
matched according to age (2-level, 41.0 years and 1-level, 40.9 years), gender (2-level, $36 \%$ male and $64 \%$ female and 1-level, $37 \%$ male and $63 \%$ female), type of total disc replacement (SB Charite' III prosthesis), level of disc replacement (L3/L4: 2 TDR in 2-level group, 2 prosthesis in 1-level group; L4/L5: 11 artificial discs in 2-level, 10 in 1-level; L5-S1: 12 prosthesis in 2-level, 11 in 1-level), average follow-up (2-level, 39.5 months and 1-level, 40.1 months). In the 2-level group, the mean time of surgery was $240 \mathrm{~min}$, mean peri- and postoperative bleeding was $402 \mathrm{ml}$, and mean hospital stay was 6.5 days. In the 1-level group, the mean time of surgery was $150 \mathrm{~min}$, mean peri- and postoperative bleeding was $180 \mathrm{ml}$ blood loss, and mean hospital stay was 5.4 days.

Functional outcome

\section{VAS scores (Fig. 1)}

The 2-level disc replacement patients presented a preoperative VAS score of 77.6 with a reduction to 41.4 at 12 months; this decrease was followed by a rise in VAS to 46.8 at the 3-year follow-up, with a VAS decrease of $39.6 \%$. Patients with 1-level disc replacements presented a preoperative VAS pain score of 70.1, which was reduced to 43.2 at 12 months and was 36.3 at the 3-year follow-up; this was a decrease of $48.2 \%$. There was no statistically significant difference between 1- and 2-level arthroplasties at 12 months $(P=0.28)$ and at 3 years $(P=0.17)$.

\section{ODI scores (Fig 2)}

The 2-level disc replacements started with an ODI of 65.2 with a decline to 45.1 at 12 months and to 44.7 at the 3-year follow-up, corresponding to an ODI decrease of $31.2 \%$. The 1-level total disc replacements presented a

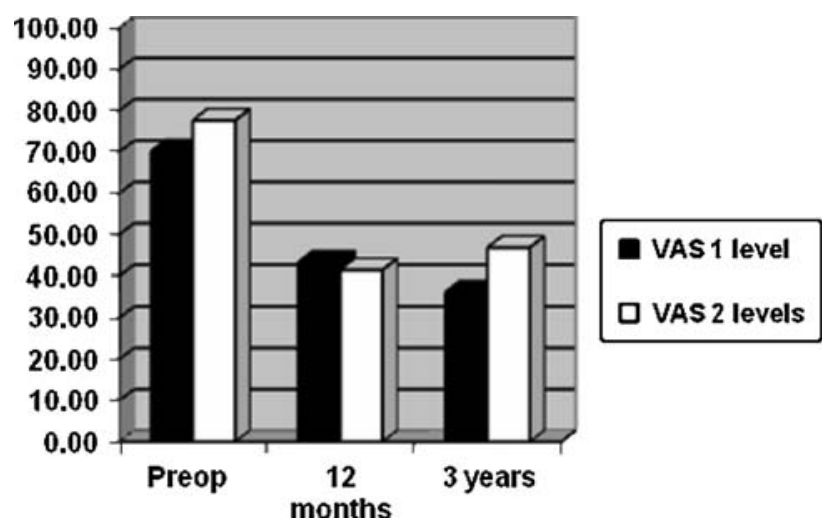

Fig. 1 VAS scores. There was no statistically significant difference between 1 - and 2-level TDR VAS scores at 12 months $(P=0.28)$ and at 3 years $(P=0.17)$

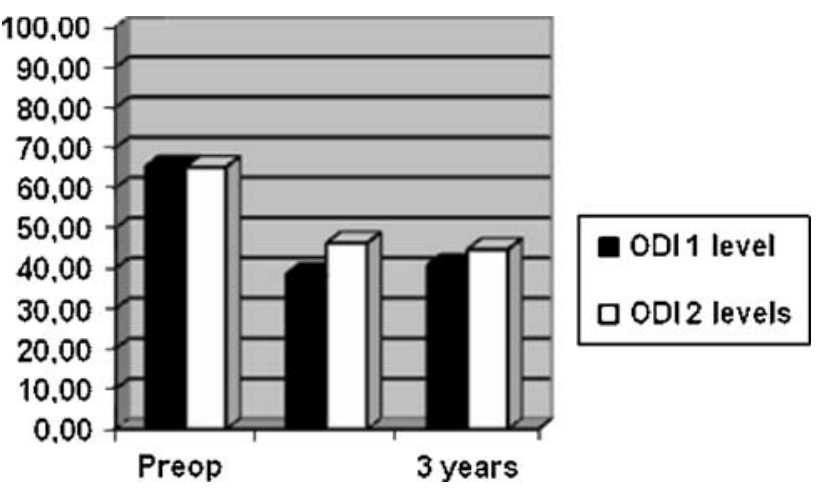

Fig. 2 ODI scores. There was no statistical significance between 1 - and 2-level TDR both at 12 months $(P=0.18)$ and at 3 years $(P=0.19)$

preoperative ODI of 65.3 with a reduction to 38.6 at the 1-year follow-up, which means an ODI decrease of $40.8 \%$. There was no statistical significance between 1- and 2-level surgeries at both 12 months $(P=0.18)$ and at 3 years $(P=0.19) ; 75 \%$ of 1 -level patients improved by $>15$ points at 3 years, $6 \%$ improved by $\leq 5$ points, and none worsened. In 2-level patients, $36 \%$ improved by more than 15 points, $4 \%$ improved $<5$ points, and $8 \%$ worsened.

\section{SF-36 scores (Fig. 3)}

The 2-level disc replacements started with a Physical Component Summary (PCS) score of 31.9 followed by 39.1 at 12 months and reaching 39.9 at 3 years, with an increase of $20 \%$. SF-36 data show that before surgery 1-level disc replacements presented a PCS score of 31.2, increasing to 37.4 at 12 months before reaching 38.7 at the 3-year follow-up, with an increase of $19.3 \%$. In this case, data also presented insignificant differences at both 1 year $(P=0.39)$ and 3 years $(P=0.96)$ between $1-$ and 2-levels.

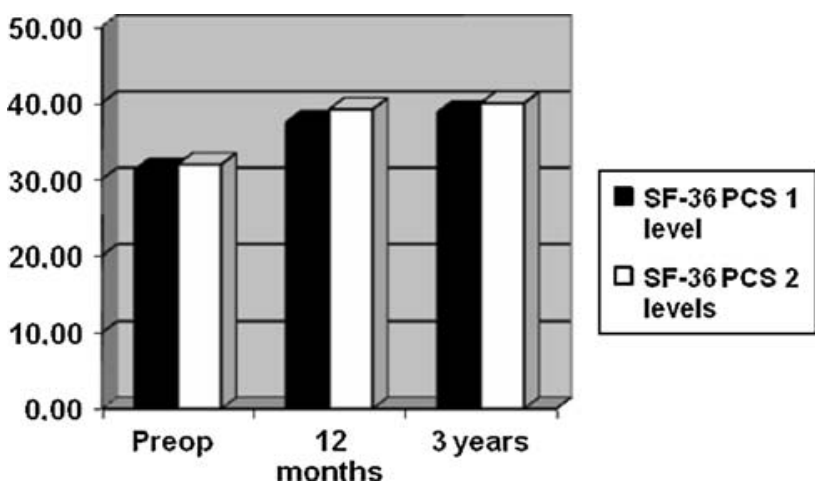

Fig. 3 SF-36 scores. In this case data also presented insignificant differences both at 1 year $(P=0.39)$ and 3 years $(P=0.96)$ between 1- and 2-levels TDR 


\section{Level of satisfaction}

The 2-level patients described their post-surgical level of satisfaction at $65.3 \%$ at 12 months and at $62.3 \%$ at 3 years. The 1-level arthroplasty patients described their post-surgical level of satisfaction at $75.6 \%$ at 12 months and at $73.9 \%$ at 3 years. This shows a statistically insignificant difference between 1 - and 2-level surgeries at the last follow-up $(P=0.46)$.

\section{Radiographic analysis}

\section{Disc height}

Patients with 2-level arthroplasty presented a median preoperative height of the affected discs of $5.1 \mathrm{~mm}$. About $90 \%$ of patients had at least $70 \%$ disc height loss compared with adjacent normal levels. At follow-up, disc heights were on an average increased to $10.9 \mathrm{~mm}$ (SD: 1.34; $P<0.001)$.

Patients with 1-level arthroplasty presented a median preoperative height of the affected discs of $5.4 \mathrm{~mm}$. About $96 \%$ of patients had at least $70 \%$ disc height loss compared with adjacent normal levels. At follow-up, disc heights were on an average increased to $11.5 \mathrm{~mm}$ (SD: 1.304; $P<0.001)$. The heights of the adjacent-level discs were not significantly changed $(P=0.76)$.

\section{Range of motion}

Patients with 2-level arthroplasty presented an increase of motion of the affected discs in flexion and extension from $2^{\circ}$ before surgery to $6.7^{\circ}$ at last follow-up (SD: 4.11; $P<0.001)$. In 1 -level TDR cases motion of the affected discs in flexion and extension was increased from $2^{\circ}$ before surgery to $6.9^{\circ}$ at follow-up (SD: $4.09 ; P<0.001$ ).

\section{Adjacent disc degeneration}

There were no signs of degenerative changes of the adjacent segments in any of the 2- or 1-level arthroplasties.

\section{Complications}

\section{2-level TDR}

In 16 cases of the 2-level group, there were 5 minor complications $(31.25 \%)$. An intraoperative tear in the iliac vein $(6.25 \%)$ was repaired primarily. In the postoperative period 1 patient $(6.25 \%)$ experienced an ileus, which was successfully treated with drugs. Two more cases $(12.5 \%)$ presented a severe post-operative anemia, which required blood transfusions: the causes of anemia were not clear, because they presented an intraoperative blood loss that resulted similar to other 2-level cases $(200$ and $250 \mathrm{ml}$, respectively) and a post-operative TC excluded a retroperitoneal bleeding. Another patient $(6.25 \%)$ presented a persistent sciatica and required steroid treatment for a continued radiculopathy. Major complications occurred in 4 more cases $(25 \%)$ and required a revision surgery in 2 patients $(12.5 \%)$. A partial implant subsidence occurred in a 32-year-old female with bisegmental L4-L5 and L5-S1 implants: the subsidence of the superior component of L5$\mathrm{S} 1$ prosthesis was noted on postoperative $\mathrm{X}$-rays and remained stable at follow-up without pain. In another 35year-old female with bisegmental L4-L5 and L5-S1 implants (Fig. 4), there was partial extrusion of the polyethylene core at L5-S1 level: it was noted on X-rays at 3 months after the index procedure and remained stable at the last visit 39 months later without clinical consequences. Another 28-year-old woman with an L5-S1 implant was complaining of persistent low-back pain, 22 months after surgery, which resolved after a cast worn for 2 weeks: she was treated by pedicular instrumentation and fusion at the same levels of total disc replacement. Laparocele of the abdominal wall occurred in a 42-year-old woman treated with a bisegmental L3-L4 and L4-L5 disc replacement: it was noted 2 weeks after the index procedure for persisting bleeding of the wound and required surgical repair of the lesion.

\section{1-level TDR}

In 1-level cases there were 2 minor complications (12.5\%); a persistent postoperative sciatica in both patients, that resolved after 2 weeks of steroid treatment. There were 2 major complications $(12.5 \%)$ and a new revision surgery was required in 1 patient $(6.25 \%)$. Partial subsidence of the superior component of a monosegmental L5-S1 occurred in a 36-year-old woman; the subsidence was observed on postoperative X-rays and remained stable at follow-up without clinical consequences. A 32-year-old female was complaining of persistent low-back pain 23 months after surgery, which resolved completely after a cast worn for 2 weeks; she was treated with a pedicular screw fixation and fusion at the same level of the index procedure.

\section{Discussion}

Total lumbar disc replacement is a controversial alternative to lumbar fusion in the treatment of degenerative disc disease [31]. Results from prospective randomised trials have shown non-inferiority of arthroplasty with SB Charitè prosthesis over fusion with BAK-cages for monosegmental 
A

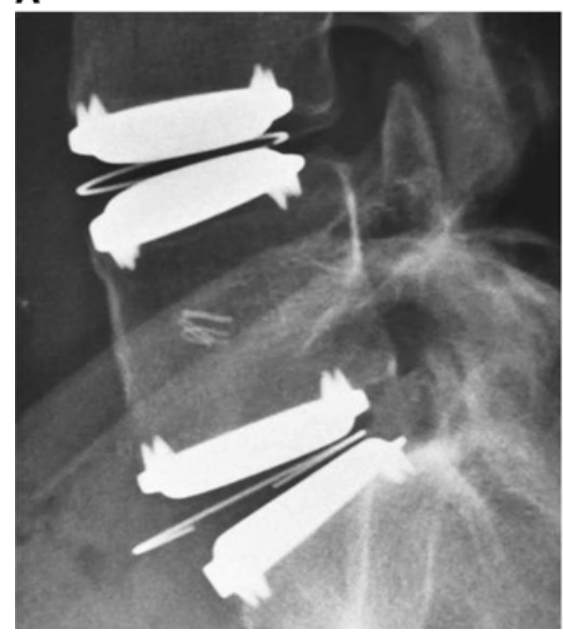

B

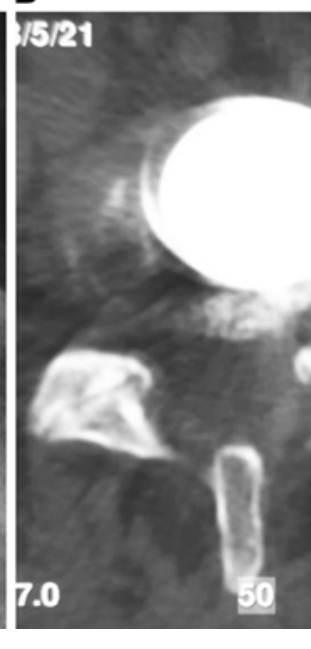

Fig. 4 Sample of a 35-year-old female. 2-level L4-L5 and L5-S1 SB Charite' III prosthesis. There was partial extrusion of the polyethylene core at L5-S1 level: it was noted on X-rays at 3 months after the

disc disease at L4-L5 and L5-S1 [4]. However, long-term results with SB Charite' disc replacement $[19,26]$ have shown less favourable results than previous studies with short- and mid-term follow-up [6, 10, 12]. In the study by Putzier et al. [19] patients with SB Charitè total disc replacement presented an incidence of $17 \%$ of cases with significant degenerative changes of the adjacent segments at 17-year follow-up: however, these adjacent alterations were found only in patients, where spontaneous ankylosis of the treated segments or fusion after implant failure occurred. However, in another study [9] with SB Charite' prosthesis, the adjacent-level reoperation rate was lower (2.8\%) corresponding to 3 cases out of 106 patients, at a mean follow-up of 13.2 years: two patients experienced a disc herniation above the index surgical level and were treated with microdiscectomy at 4 and 5 years postsurgery, respectively, and another case developed spinal stenosis 5 years after the index procedure and required a decompression and fusion procedure. Using different artificial disc replacements, adjacent-level degeneration has been reported in the literature in different studies [2, 14, 16, 22] with follow-ups of more than 3 years with an incidence rate that ranges between $9.2 \%$ [2] to $24 \%$ [14] and to $28.6 \%$ [22]: these results suggest that disc arthroplasty may not have a protective effect on the adjacent segments as initially thought. The mid-term results of our series at 3 years follow-up did not confirm this conclusion, since we did not find cases of adjacent-level degeneration, as reported by Cinotti et al. [6], in 3.2 years follow-up based on MRI. It may take, however, more than a decade for symptomatic junctional degeneration to develop: a longer follow-up may be required in our patients to exclude the onset of the adjacent degeneration reported in the literature. index procedure and remained stable at the last visit 39 months later without clinical consequences $(\mathbf{a}, \mathbf{b})$

Bi- and multisegmental disc replacement showed less favourable results than monosegmental disc arthroplasty for some authors [5, 6, 23]. In our series it was impossible to delineate a clear difference in evaluating the questionnaires between the follow-up results of patients receiving 1- and 2-level disc prosthesis: these results are in agreement with previous studies with ProDisc II TDR [13, 30]. However, the 2-level group presented slightly lower scores at follow-up in our series, but none was statistically significant.

Bisegmental TDR can determine an increased loading of sacroiliac and facet joints. It is not clear; however, if this might have a negative mid- and long-term impact on clinical outcome. Trouillier et al. [25] studied the effects of monosegmental Charitè artificial disc on facet joint loads in patients at 6 and 12 months follow-up and concluded that arthroplasty was not associated with increased loading of the facet joints at the treated or adjacent levels; however, this is a small short-term series and long-term data are necessary to confirm these results. The overload of the posterior structures (facet sacroiliac joints) was highlighted by Siepe et al. [23] with 2-level disc replacement: this overload might lead to unsatisfactory results, due to the onset of pain at longer follow-ups. Analysing unsatisfactory functional results, authors [23] concluded that posterior joint structures, such as iliosacral and facet joints, are the most common cause of postoperative back pain; they performed a failure analysis using fluoroscopically-guided infiltrations: the incidence of pain originating from posterior structures increased from $9.1 \%$ (when TDR was performed monosegmentally at L4-L5) and $28.1 \%$ (following L5-S1 disc replacement) to $60 \%$ for bisegmental TDR at L4-L5 and L5-S1. Another study with an 11.3year follow-up [16] showed secondary progression of 
osteoarthritic changes in about $10 \%$ of all cases, which were seen as a possible reason for unsatisfactory outcome. Furthermore, a recent kinematic radiographic study [7] showed normal values for axial rotation when TDR was performed monosegmentally, whereas abnormally increased mobility was found following bisegmental TDR in $50 \%$ of cases compared with results reported for healthy volunteers: the replacement of only one disc as opposed to bisegmental TDR seems to restore normal kinematics.

However, the source of pain from posterior structures following bisegmental lumbar disc replacement is not clear. In the past similar pain patterns were observed at follow-up control after lumbar fusion. Siepe et al. [23] used fluoroscopically-guided infiltrations, which revealed pain from the facet and iliosacral joints as the most common cause of unsatisfactory outcome. Le Huec et al. [15] implanted Maverick prosthesis (a semiconstrained TDR with a fixed posterior centre of rotation): they performed facet infiltrations in 17 out of 64 patients treated by monosegmental disc replacement and 11 of them had a positive reaction. In our experience it was common to use a cast for 2 weeks on average; a positive relief of pain was the confirmation for the choice of a fusion procedure in cases with persistent pain after TDR.

Bisegmental disc replacements presented an increase of complications in comparison with monosegmental disc arthroplasty in literature [23]. These results are in agreement with those of our series. In our study the use of 2-level disc replacement at last follow-up presented a higher incidence of complications than in cases with 1-level prosthesis: in patients with 2-level TDR, there were 5 minor complications $(31.25 \%)$ and 4 major complications $(25 \%)$, that required a revision surgery in 2 cases (12.5\%); in 1-level TDR cases there were 2 minor complications (12.5\%) and 2 major complications $(12.5 \%)$, requiring a new fusion procedure in 1 patient $(6.25 \%)$. This rate of complications is in agreement with previous papers on TDR surgery, which presented a wide range of complications, more often ranging from $10 \%$ to $20 \%[6,15,16,24]$. However, our results of reoperation rate in 2-level patients increased in comparison with the results of recent large series, which reported a reoperation rate of $8.8 \%$ [17] and $8.1 \%$ [23]. Therefore, care should be taken when lumbar disc replacement is performed bisegmentally. In the future the option of an anterior hybrid strategy for two levels lumbar degenerative disc disease should also be taken in account, using a TDR at one level and an interbody fusion at the adjacent one.

\section{Conclusion}

In our study we compared the results of 2- versus 1-level disc replacement patients who had at least 3 years of follow-up. The results revealed an increase in postoperative complications, when TDR included 2-level in comparison with monosegmental disc replacement.

In evaluating the questionnaires between the follow-up results of patients receiving 2- and 1-level disc prosthesis, it should be underlined that the 1-level group presented both better scores and level of patient's satisfaction, nevertheless the difference was not statistically significant.

Acknowledgments No funds were received in support of this study.

Conflict of interest statement None of the authors has any potential conflict of interest.

\section{References}

1. Apolone G, Mosconi P, Ware JE (1997) Questionario sullo stato di salute SF-36. Guerini e Associati, Milano

2. Bertagnoli R, Kumar S (2002) Indications for full prosthetic disc arthroplasty: a correlation of clinical outcome against a variety of indications. Eur Spine J 11(Suppl 2):131-136

3. Bertagnoli R, Yue JJ, Shah RV, Nanieva R, Pfeiffer F, FenkMayer A, Kershaw T, Husted DS (2005) The treatment of disabling multilevel lumbar discogenic low back pain with total disc arthroplasty utilizing the ProDisc prosthesis. A prospective study with 2-year minimum follow-up. Spine 30:2192-2199

4. Blumenthal S, McAfee PC, Guyer RD et al (2005) A prospective, randomized, multicenter Food and Drug Administration investigational device exemptions study of lumbar total disc replacement with the CHARITÉ artificial disc versus lumbar fusion: part I: evaluation of clinical outcomes. Spine 30:1565-1575

5. Chung SS, Lee CS, Kang CS (2006) Lumbar total disc replacement using ProDisc II: a prospective study with a 2-year minimum follow-up. J Spinal Disord Tech 19:411-415

6. Cinotti G, David T, Postacchini F (1996) Results of disc prosthesis after a minimum follow-up period of 2 years. Spine 21:995-1000

7. Cunningham BW, Gordon JD, Dmitriev AE (2003) Biomechanical evaluation of total disc replacement arthroplasty: an in vitro human cadaveric model. Spine 28(Suppl):110-117

8. David T (1993) Lumbar disc prosthesis: surgical technique, indications and clinical results in 22 patients with a minimum of 12 months follow-up. Eur Spine J 1:254-259

9. David T (2007) Long-term results of one-level lumbar arthroplasty: minimum 10-year follow-up of the CHARITÉ artificial disc in 106 patients. Spine 32:661-666

10. Enker P, Steffee A, McMillin C, Kepler L, Biscup R, Miller S (1993) Artificial disc replacement: preliminary report with a 3year minimum follow-up. Spine 18:1061-1670

11. Fairbank JC, Couper J, Davies JB et al (1980) The Oswestry low back pain disability questionnaire. Physiotherapy 66:271-273

12. Griffith SL, Shelokov AP, Buttner-Janz K, LeMaire JP, Zeegers WS (1994) A multicenter retrospective study of the clinical results of the LINK SB Charite intervertebral prosthesis: the initial European experience. Spine 19:1842-1849

13. Hannibal M, Thomas DJ, Low J, Hsu KY, Zucherman J (2007) ProDisc-L total disc replacement a comparison of 1-level versus 2-level arthroplasty patients with a minimum 2-year follow-up. Spine 32:2322-2326

14. Huang RC, Tropiano P, Marnay T et al (2006) Range of motion and adjacent level degeneration after lumbar total disc replacement. Spine J 6:242-247 
15. Le Huec JC, Basso Y, Aunoble S, Friesem T, Brayda-Bruno M (2005) Influence of facet and posterior muscle degeneration on clinical results of lumbar total disc replacement: two-year followup. J Spinal Disord Tech 18:219-223

16. Lemaire JP, Carrier H, Ali el-HS et al (2005) Clinical and radiological outcomes with the Charité trade mark artificial disc: a 10-year minimum follow-up. J Spinal Disord Tech 18:353-359

17. McAfee PC, Cunningham B, Holsapple G, Adams K et al (2005) A prospective, randomized, multicenter Food and Drug Administration investigational device exemption study of lumbar total disc replacement with the CHARITÉ artificial disc versus lumbar fusion: part II: evaluation of radiographic outcomes and correlation of surgical technique accuracy with clinical outcomes. Spine 30:1576-1583

18. Patel AA, Brodke DS, Pimenta L, Bono CM, Hilibrand AS, Harrop JS, Riew KD, Youssef JA, Vaccaro AR (2008) Revision Strategies in lumbar Total Disc Arthroplasty. Spine 33:12761283

19. Putzier M, Funk JF, Schneider SV et al (2006) Charitè total disc replacement-clinical and radiographical results after an average follow-up of 17 years. Eur Spine J 15:183-195

20. Roland M, Fairbank JC (2000) The Roland-Morris disability questionnaire and the Oswestry disability questionnaire. Spine 25:3115-3124

21. Sachs BL, Vanharanta H, Spivey MA et al (1987) Dallas discogram description: a new classification of $\mathrm{CT} /$ discography in low back disorders. Spine 12:287-294

22. Shim CS, Lee SH, Shin HD et al (2007) Charité versus ProDisc: a comparative study of a minimum 3-year follow-up. Spine 32:1012-1018
23. Siepe CJ, Mayer HM, Heinz-Leisenheimer M, Korge A (2007) Total lumbar disc replacement: different results for different levels. Spine 32:782-790

24. Tropiano P, Huang RC, Federico PG et al (2005) Lumbar total disc replacement: seven to eleven year follow-up. J Bone Joint Surg Am 87:490-496

25. Trouillier H, Kern P, Refior HJ, Muller-Gerbl M (2006) A prospective morphological study of facet joint integrity following intervertebral disc replacement with the Charitè artificial disc. Eur Spine J 15:174-182

26. Van Ooij A, Oner FC, Verbout AJ (2003) Complications of artificial disc replacement a report of 27 patients with SB Charitè disc. J Spinal Disord Tech 16:369-383

27. Zeegers WS, Bohnen LM, Laaper M, Verhaegen MJ (1999) Artificial disc replacement with the modular type SB Charite III: 2 -year results in 50 prospectively studied patients. Eur Spine J 8:210-217

28. Zigler J (2003) Clinical results with ProDisc: European experience and U.S. investigation device exemption study. Spine 28(Suppl):163-166

29. Zigler JE (2004) Lumbar spine arthroplasty using the ProDisc II. Spine J 4(Suppl):260-267

30. Zigler JE, Sachs BL, Rashbaum RF et al (2005) Two level total lumbar disc replacement with ProDisc: results and comparison to one level cases. In: Proceedings of the NASS 20th annual meeting. Philadelphia, PA, USA. Spine J 5(suppl 1):4-5

31. Zindrick MR, Tzermiadianos MN, Voronov LI, Lorenz M, Hadjipavlov A (2008) An evidence-based medicine approach in determining factors that may affect outcome in lumbar total disc replacement. Spine 33(11):1262-1269 